\title{
Diffusion of foraging innovations in the guppy
}

\author{
SIMON M. READER \& KEVIN N. LALAND \\ Sub-Department of Animal Behaviour, Department of Zoology, University of Cambridge \\ (Received 16 September 1999; initial acceptance 4 November 1999; \\ final acceptance 20 March 2000; MS. number: 6355)
}

\begin{abstract}
The way in which novel learned behaviour patterns spread through animal populations remains poorly understood, despite extensive field research and the recognition that such processes play an important role in the behavioural development, social interactions and evolution of many animal species. We conducted a series of controlled diffusions of foraging information in replicate experimental populations of the guppy, Poecilia reticulata. We presented novel foraging tasks over 15 trials to mixed-sex groups, made up of food-deprived and nonfood-deprived adults (experiment 1) or small, young fish and old, large adults (experiment 2). In these diffusions, knowledge of a route to a feeder could spread through the group by subjects learning from others, discovering the route for themselves, or, most likely, by some combination of these social and asocial learning processes. We found a striking sex difference, with novel foraging information spreading at a significantly faster rate through subgroups of females than of males. Females both discovered the goal and learned the route more quickly than males. Food-deprived individuals were faster at completing the tasks over the 15 trials than nonfood-deprived guppies, and there was a significant interaction between sex and size, with a sex difference in adults but not young individuals. There was also an interaction between sex and hunger level, with food deprivation having a stronger effect on male than female performance. We suggest that information may diffuse in a similar nonrandom or 'directed' manner through many natural populations of animals.
\end{abstract}

(ㄷ) 2000 The Association for the Study of Animal Behaviour

Numerous observations of natural animal populations report the diffusion of behavioural innovations, for example, milk-bottle opening in birds and food washing in macaques (Fisher \& Hinde 1949; Kawai 1965). Such novel behaviour patterns include the exploitation of new food sources, entry into unknown spaces, or learning to use novel tools (Itani 1965; Katzir 1982; Fragaszy \& Visalberghi 1989; Lee 1991). The key characteristic of innovation is the introduction of a novel behaviour pattern into a population's repertoire. Among humans, diffusion is defined as the process by which an innovation is communicated through certain channels over time among the members of a social system' (Rogers 1995, page 5). In other animals too, it is usually assumed that the diffusion of innovations is the result of social learning processes, where individuals learn by observing or interacting with other animals (Box 1984; Heyes 1994). However, this is rarely proven and asocial learning processes may be sufficient to account for many such phenomena (Galef 1992). Here we use the term diffusion to refer to the increase in frequency of a

Correspondence and present address: S. M. Reader, Bellairs Research Institute of McGill University, St James, Barbados, West Indies (email: simon.reader@ukonline.co.uk).K. N. Laland is at the Sub-Department of Animal Behaviour, Madingley, Cambridge CB3 8AA, U.K.

0003-3472/00/080175+06 \$35.00/0 novel learned behaviour, irrespective of the processes involved.

Empirical scientists and theoreticians alike have tended to assume that individuals in a population are equally likely to learn or transmit information (Cavalli-Sforza \& Feldman 1981; Boyd \& Richerson 1985; Coussi-Korbel \& Fragaszy 1995). Theoretical models predict that the cumulative number of individuals displaying a novel behaviour over time will follow a sigmoidal pattern (Cavalli-Sforza \& Feldman 1981; Boyd \& Richerson 1985; but see Lefebvre 1995a). With notable exceptions (Lefebvre \& Palameta 1988; Fragaszy \& Visalberghi 1990; Lefebvre 1995a,b), empirical data are lacking both on the validity of these assumptions and the dynamics of diffusion processes. Field studies of isolated diffusions lack replication, and are frequently based on observations of small numbers of animals recorded over long periods of time. As a result, such reports yield data of questionable reliability for the study of the dynamics of information flow.

Recently Coussi-Korbel \& Fragaszy (1995) have suggested that animals are likely to attend to, and learn from, certain individuals in preference to others, a phenomenon they refer to as 'directed' social learning. There is clear experimental evidence that individuals in many 
species associate together in a nonrandom manner, restricting the routes by which information is likely to flow through the population (Coussi-Korbel \& Fragaszy 1995; Griffiths \& Magurran 1997; Lachlan et al. 1998). We anticipate that factors such as sex, age, size, dominance and hunger level may cause differences between individuals in the likelihood of both learning and transmitting information, and hence may alter the way information diffuses.

We investigated the effects of sex, age and hunger level on the spread of novel foraging information in two experiments on replicate groups of guppies, Poecilia reticulata. We chose guppies, small tropical fish endemic to northeastern South America, both because experimental evidence for social learning is strong (Sugita 1980; Laland \& Williams 1997, 1998; Lachlan et al. 1998) and because their size and social structure (Magurran et al. 1995) allowed us to manipulate demography and observe the discovery and spread of novel information within the laboratory environment over weeks rather than years. We investigated diffusion by recording the rate at which different individuals in groups learned to complete a foraging task. The groups contained guppies that varied with respect to sex, age and hunger level. Although social learning is implicated in the investigation, we did not attempt to determine the relative contributions of social and asocial learning processes to the diffusion dynamics.

\section{METHODS}

The methods for experiments 1 and 2 are identical. In both cases subjects were required to swim a maze task to find food. In each experiment we tested three groups of guppies, with each group presented with a different novel foraging task for 15 trials. In experiment 1 the groups contained equal numbers of males and females, and equal numbers of food-deprived and nonfooddeprived fish. Hence there were three between-subject variables (sex, hunger level and group) and one withinsubject variable (trial). Experiment 2 replicated experiment 1 but used size rather than hunger level as an independent variable. This experiment tested three groups made up of equal numbers of males and females, and equal numbers of small, young guppies and larger, older fish.

\section{Subjects and Apparatus}

We used 116 guppies, 60 in experiment 1 and 56 in experiment 2, purchased from Neil Hardy Aquatics, London, U.K. Domestic guppies were used because, unlike wild guppies, both sexes have distinctive colour markings, so we could identify all individuals while avoiding stressful marking procedures. Subjects were housed in experimental tanks of size $60 \times 30 \mathrm{~cm}$ and $33 \mathrm{~cm}$ high. All tanks were maintained at $25 \pm 2{ }^{\circ} \mathrm{C}$, and had a water depth of $30 \mathrm{~cm}$. The fish were on a 12:12 h light:dark schedule, with lights on at 0700 hours; additional red lights were on continuously, so that the change in lighting was less disturbing to the fish.

In experiment 1 we examined three groups, each of 20 fish, with each group presented with one of three mazes. One male fish in the group presented with maze 2 was initially mistakenly identified as female, so there were four nonfood-deprived females and six nonfood-deprived males in this group. Subjects in experiment 1 were not weighed, but were composed of a broad cross-section of adult sizes. A further three groups of fish were examined in experiment 2, where each tank contained equal numbers of small guppies, just old enough to determine their sex $(\bar{X} \pm \mathrm{SE}=0.24 \pm 0.03 \mathrm{~g}, N=27)$, and adult, older guppies of a similar size to those used in experiment 1 $(0.70 \pm 0.05 \mathrm{~g}, N=26)$. Fish categorized as large weighed significantly more than fish categorized as small ( $t$ test: $\left.t_{51}=7.58, P<0.0001\right)$. Females $(0.57 \pm 0.07 \mathrm{~g}, N=25)$ weighed more than males $(0.37 \pm 0.04 \mathrm{~g}, N=28$; $t$ test: $\left.t_{51}=2.33, P<0.05\right)$. In experiment 2 , the group presented with maze 1 numbered 16 fish, and the remaining two groups initially numbered 20 fish each. Two large females in the maze 3 group, however, were removed from the experiment and placed in a hospital tank for treatment when they developed fin rot. A further small female from the maze 2 group fell ill after testing was completed, so was not weighed. No other fish showed any health problems either during or after the experiment.

Over 15 trials, we repeatedly presented each experimental group with the same one of the three maze tasks, with the maze introduced into the experimental tanks. The mazes were opaque, white, uPVC dividing partitions, each containing a hole through which the fish could swim to the other end of the tank. A partition $10 \mathrm{~cm}$ in front of the maze allowed the apparatus to be set up while excluding the fish, with the raising of this partition signifying the beginning of a trial. A second partition slid directly behind the maze, being pushed down completely to close the hole once a trial had ended. The goal zone contained a concealed floating feeder of red plastic $30 \mathrm{~mm}$ in diameter and $6 \mathrm{~mm}$ deep. Small quantities (ca. eight items) of a novel high-protein food, freeze-dried bloodworm (Chironomus spp.), were placed in these feeders. This food was replenished throughout each trial, a procedure that did not appear to disturb the fish.

For maze 1 (Fig. 1a), the feeder was accessible via a centrally located hole of $5 \times 5 \mathrm{~cm}$ in the lower edge of a white, opaque, uPVC partition. For maze 2 (Fig. 1b), the fish found the feeder by swimming up a vertical plastic tunnel (height $12 \mathrm{~cm}$, entrance diameter $6 \mathrm{~cm}$ ) covered in dark green cellophane, through the same hole of $5 \times 5 \mathrm{~cm}$ and along a horizontal, clear plastic tunnel (length $8 \mathrm{~cm}$, diameter $6 \mathrm{~cm}$ ). For maze 3 (Fig. 1c), the maze apparatus of task 2 was turned upside down, so that the fish could reach the feeder by swimming down and along the tunnels. Pilot studies suggested that the three tasks were of increasing difficulty to the fish, judging by the average time to complete them. We used the three mazes to ensure that the results were not biased by ceiling or floor effects, or a consequence of very easy or very difficult tasks. 


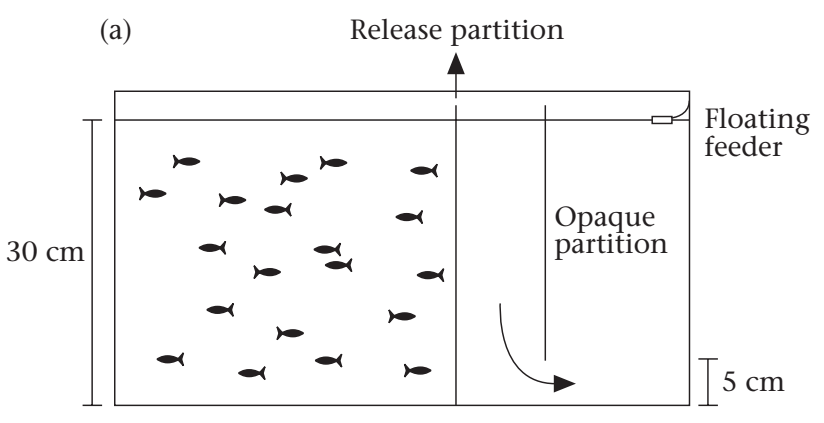

(b)

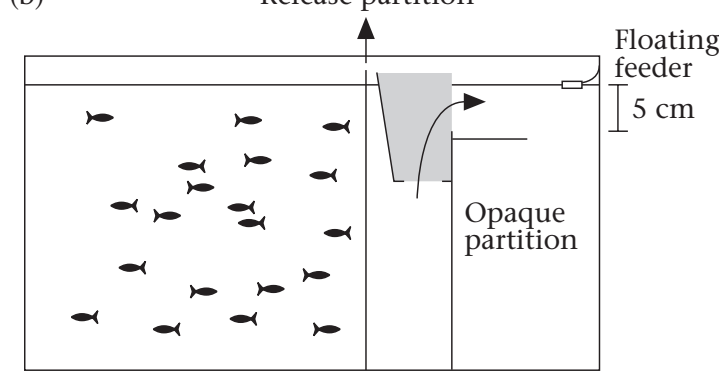

(c)

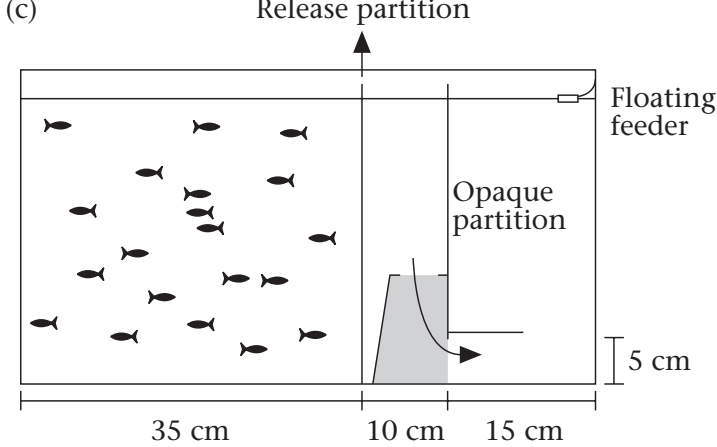

Figure 1. The foraging tasks. Side view of (a) maze 1, (b) maze 2 and (c) maze 3. The shaded areas indicate dark green, plastic tunnels. Curved arrows indicate the route fish took to complete the task. The directions in which the opaque release partitions were removed are indicated by straight arrows.

\section{Procedure}

The procedure was the same for both experiments, except that half the fish of each sex in experiment 1 were food deprived. Prior to the experiments, subjects were held in several mixed-sex holding tanks, and fed daily on standard tropical fish flakes. We chose subjects at random from these stock tanks to make up the experimental groups. In experiment 1 the experimental groups were established 5 days prior to testing; food-deprived fish were separated from nonfood-deprived fish by a double opaque PVC partition and were not fed in this period, a procedure that generated no ill effects or increased mortality. Nonfood-deprived fish were fed $4 \mathrm{~h}$ before testing began. In experiment 2, the experimental groups were established $24 \mathrm{~h}$ before testing. From the first day of testing, and for 5 consecutive days, we presented each group with a novel foraging task, the location of a feeder hidden behind a maze partition. We tested subjects at 0900, 1300 and 1700 hours each day. Prior to each trial an opaque partition was placed in the enclosure and pushed to a central position. The maze apparatus was then inserted into the section of the tank containing no fish, at a position ca. $15 \mathrm{~cm}$ from the end of the tank. A floating feeder containing freeze-dried bloodworm was positioned centrally on the other side of the maze to the fish. Each trial began with the removal of the partition concealing the maze, and ended $10 \mathrm{~min}$ (maze 1) or 20 min (mazes 2 and 3) later with the removal of the apparatus. After each trial we fed the fish a small amount of tropical fish flake food to minimize hunger differences between unsuccessful and successful fish. We recorded the time to complete the maze ('latency') for each subject on each trial.

\section{Statistical Analysis}

Although guppies are loose shoalers and not schooling fish with coordinated movements (Seghers 1974), we cannot assume that the fish behaved independently, as the fish within a group do influence each other's activity levels, location and physical condition to some degree. Consequently, in our analysis we adopted a hierarchically structured ANOVA design that included a 'group' factor. This factor partialled out any between-group variance caused by the group structure, as well as accounting for differences between groups resulting from the alternative maze tasks. Where appropriate, data were log transformed to meet required assumptions of homogeneity of variance and normality of residuals.

\section{RESULTS}

Figure $2 \mathrm{a}$ shows the latency to complete the foraging tasks over 15 trials in food-deprived and nonfooddeprived males and females. Females were significantly faster than males (repeated measures ANOVA: $F_{1,48}=$ $60.35, P<0.0001$ ) and food-deprived fish significantly faster than nonfood-deprived fish (repeated measures ANOVA: $\left.F_{1,48}=4.90, P<0.05\right)$. The sexes differed in their response to food deprivation (repeated measures ANOVA, sex $\times$ hunger: $\left.F_{1,48}=4.46, P<0.05\right)$, food deprivation having a greater effect on male latency than female latency, although the sex difference was significant in both fooddeprived and nonfood-deprived subjects (Tukey test on log-transformed data: difference $=0.95$, critical $W_{r}=$ $0.59, \quad P<0.05$; difference $=1.70$, critical $W_{r}=0.36, P<$ 0.05 , respectively). Mean latency to complete the task decreased over time (trend test: $F_{1,30}=37.92, P<0.01$ ), apparently because of a combination of increasing numbers of subjects completing the task (nonparametric trend test, corrected for ties, Ferguson 1965: $Z=3.98, P<0.0002$ ) and a decrease in the time each subject took to complete the maze. Subjects in the different subgroups behaved similarly across the three mazes.

Further evidence that our results cannot be dismissed as artefacts reflecting the reduced degrees of freedom that would result from schooling is provided by the observation that the sex difference remained significant when 


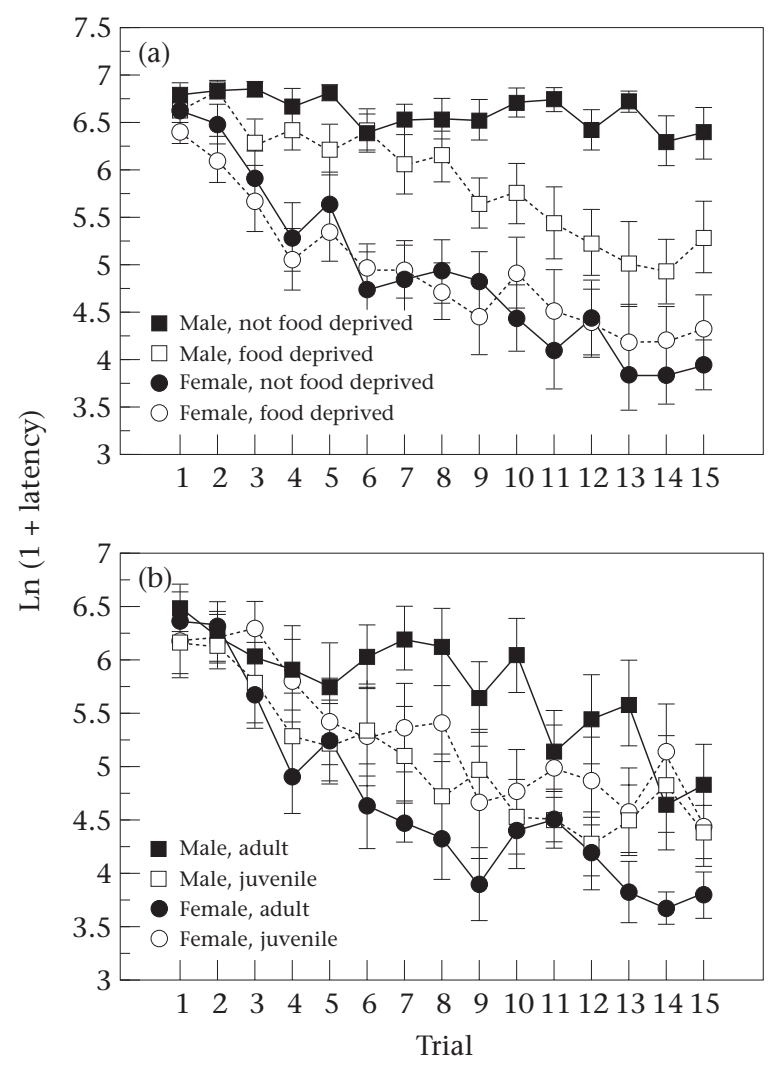

Figure 2. Log-transformed mean latency (s) to enter goal zone against trial for (a) food-deprived and nonfood-deprived fish and (b) adult and juvenile fish. In (a) $N=60$, made up of three groups of 20 fish each; in (b) $N=54$, made up of three groups of 20, 18 and 16 fish. Vertical bars indicate SE.

the mean latencies of each sex in each group were analysed rather than the latencies for each individual fish (repeated measures ANOVA: $F_{1,8}=10.20, P<0.05$ ). To the extent that the mean latencies for males and females within each group are not independent of one another, this dependence will act only to weaken any genuine sex difference. The fact that a significant difference between the sexes was found under this most conservative of all measures suggests that the effect is particularly robust.

To investigate whether there were sex and hunger differences in exploratory behaviour or innovation, we focused on the first few trials of the experiment. If females and hungry fish were more innovatory than males and food-deprived fish, respectively, then they should be more likely to discover the feeder for the first time early in testing, and differences should be present over the first five trials and on the first trial. Females were significantly faster than males and food-deprived fish significantly faster than nonfood-deprived fish during the first five trials (repeated measures ANOVA: $F_{1,48}=30.94$, $\left.P<0.0001 ; F_{1,48}=5.70, P<0.05\right)$, perhaps indicative of a greater exploratory tendency in females and fooddeprived fish. Analysis of the first trial alone examines exploration without learning but provides less statistical power. None the less, there was a significant difference for hunger level (ANOVA: $F_{1,48}=4.64, P<0.05$ ) and the sex

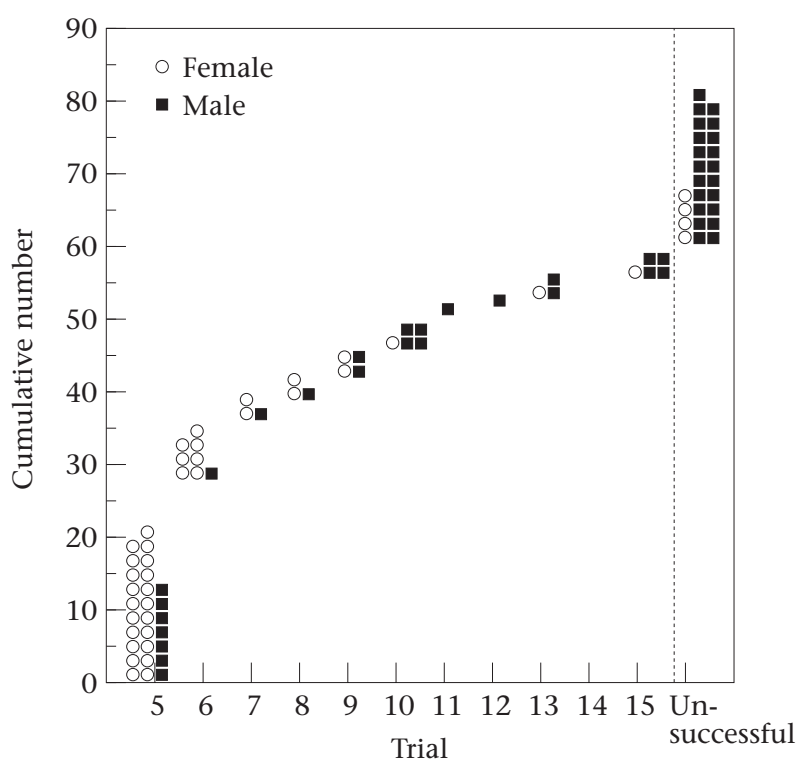

Figure 3. Cumulative number of adult females and males from experiments 1 and 2 reaching a learning criterion. Subjects that did not reach the learning criterion within 15 trials are shown on the right-hand side of the dashed line. $N=86$.

difference approached significance (ANOVA: $F_{1,48}=3.42$, $P<0.1)$.

In an attempt to separate the effects of innovation and learning, we also carried out an analysis of the five trials after an individual completed a task for the first time. Once individuals had discovered the route to the feeder, if there were no differences in latency between categories in the trials that immediately followed, this would imply that those differences found across all trials resulted from differences in innovation (that is, latency to find the feeder first) rather than in learning rate. This was not the case. The learning measure gave a significant effect of sex (repeated measures ANOVA: $F_{1,48}=50.28, P<0.0001$ ), females again showing lower latencies than males, but not hunger level (repeated measures ANOVA: $F_{1,48}=$ 0.86 , NS). It would seem that females were both more innovatory, and learnt at a faster rate, than males.

We examined learning differences further using a trialsto-criterion measure, which better illustrates the extent of the sex difference (Fig. 3). The criterion we adopted was completion of the task in three out of four trials in significantly less time than the group mean for trial 1 . That is, for each subject on each trial we calculated whether the task was completed in significantly less time than the time taken by that group on the first trial, which we felt could be used as an indicator that a subject had learned the task. The more intuitive alternative approach, that of choosing an arbitrary time below which subjects are considered to have 'learned', would not account for performance differences between mazes. As a subject may complete the task quickly on one trial by chance or by following another fish, we set a criterion that the subject had completed the task within the target time on three out of four trials to ensure we had a reasonable estimate of when subjects had learned the task. In both experiments 
1 and 2, females reached the learning criterion in fewer trials than males (censored actuarial survivorship analysis, log-rank test: $\chi_{1}^{2}=16.05, P<0.0001 ; \chi_{1}^{2}=4.69, P<0.05$; respectively) but no difference for hunger level or size was found (log-rank test: $\chi_{1}^{2}=2.63$, NS; $\chi_{1}^{2}=1.19$, NS; respectively). Figure 3 shows a compelling sex difference, with adult females occupying the early parts of the curve relative to adult males. In some groups there was a total lack of overlap between the two sexes, with all of the females learning the task before even the first male had successfully reached criterion.

Experiment 2 reinforces these findings (Fig. 2b). Once again females were significantly faster than males (repeated measures ANOVA: $\left.F_{1,42}=6.76, \quad P<0.05\right)$. Although there was no main effect of size (repeated measures ANOVA: $F_{1,42}=0.55$, NS), a significant sex $\times$ size interaction was discovered (repeated measures ANOVA: $\left.F_{1,42}=14.02, P<0.001\right)$. Adult females were much faster than adult males (Tukey test on log-transformed data: difference $=1.06$, critical $\left.W_{r}=0.47, P<0.05\right)$ but no sex difference was found in juveniles (Tukey test on logtransformed data: difference $=0.24$, critical $\left.W_{r}=0.40, \mathrm{NS}\right)$. Since male guppies are typically smaller than females (Magurran et al. 1995), the sex difference found in experiment 1 cannot be explained as resulting from differences in mass since large males showed longer, not shorter, latencies to complete the task than small males (Tukey test on log-transformed data: difference $=0.69$, critical $\left.W_{r}=0.39, P<0.05\right)$. Hence if experiment 1 was conducted with the sexes perfectly matched for size, we might expect an even stronger sex difference. It is also implausible to explain the sex difference as resulting from a difference in activity level between the sexes. Although activity levels were not recorded formally, casual observation suggested that males were more active than females, and there was no evidence for males being less active than females. Again, mean latency to complete the task decreased over time (trend test: $F_{1,30}=14.58$, $P<0.01)$ and the numbers of subjects completing the task increased over time (nonparametric trend test, corrected for ties: $Z=5.67, P<0.0001)$. Subjects in the different subgroups behaved similarly across the three mazes.

\section{DISCUSSION}

Our experiments provide clear evidence that, in guppies, novel learned foraging information spreads through female subgroups faster than through male subgroups. Several processes may combine to account for these differences. Female guppies are more innovatory and exploratory than males in foraging tasks (Laland \& Reader 1999a), and the finding of significant sex differences over the first few trials in this study supports this conclusion. We also found that females learn at a faster rate than males, which may reflect a motivational difference between the sexes. We did not set out to establish categorically whether social learning was involved in the diffusion. However, the fact that previous studies have found that guppies are able to learn the route to a food source by following conspecifics through a maze (Laland
\& Williams 1997) implicates social learning as a likely factor in these diffusions.

We suggest that parental investment asymmetries in guppies could be responsible for this sex difference. It is well established that where males provide only sperm, male reproductive success is mainly limited by access to females, while female reproductive success is mainly limited by access to resources (Trivers 1972; Davies 1991). The more food resources a female guppy can gather, the more offspring she can produce (Dussault \& Kramer 1981; Constanz 1989; Reznick \& Yang 1993). Hence, to maximize their respective fitness payoffs, we may expect females to place a priority on locating resources and males on location of mates (Trivers 1972; Davies 1991). Although exploratory behaviour may be energetically costly and increase the risk of predation (Milinski 1993), female fecundity in fish increases with accelerating returns with increasing body length. In contrast, a male's ability to obtain matings appears to increase linearly or with diminishing returns with body length (Sargent \& Gross 1993). This means that a conservative foraging strategy is less likely to be adaptive in females than in males. Males may prioritize the location of resources over mates only when food deprived, consistent with the observed effect of hunger on males compared with females. The absence of a strong sex difference in younger fish is consistent with a parental investment hypothesis as young fish will not be expected to show investment asymmetries, but also with alternative hypotheses such as poor competitive ability in smaller, younger fish (Krause 1994; Laland \& Reader 1999b). Since investment asymmetries are widespread amongst mammals, birds, fish and other animals (Clutton-Brock 1991), we anticipate many species may show similar sex differences in the spread of foraging innovations. An alternative hypothesis is that female performance is enhanced, or male performance made worse, by the presence of the opposite sex. This might happen, for example, if females swim through the maze in order to escape male harassment. Griffiths \& Magurran (1998) noted that male guppies are more active than female guppies, crossing the centre of a tank (where a shoal of same-sex conspecifics was located at either end) more frequently than females, which makes sex differences in activity levels an unlikely explanation for the results observed here.

Although we cannot rule out the possibility that the domestic origin of the subjects may restrict the generality of our conclusions, we regard it as unlikely that artificial selection in the pursuit of fancy guppy strains would result in the sex differences in learning described here. Experiments comparing the behaviour of wild and domesticated guppy strains are complicated by the great behavioural variation between wild guppy populations (Endler 1995; Magurran et al. 1995), but studies are planned to confirm that similar processes operate in groups of wild guppies in the field.

It is clear that differences in sex, age and motivational state can affect the discovery, learning and diffusion of novel foraging information. Information may therefore flow preferentially through certain subsections of animal groups, not only as a result of the nonrandom 
associations individuals form, but also since individuals may differ in their propensities to innovate, learn individually or learn from others. Past neglect of these processes may help to explain why our diffusion curves give a very poor fit to the sigmoidal diffusion pattern predicted by theoretical models.

\section{Acknowledgments}

We thank P. P. G. Bateson, E. B. Keverne, J. Krause, L. Lefebvre, B. J. McCabe and two anonymous referees for helpful comments. This work was supported by a Royal Society University Research Fellowship to K.N.L. and a BBSRC studentship to S.M.R.

\section{References}

Box, H. O. 1984. Primate Behaviour and Social Ecology. London: Chapman \& Hall.

Boyd, R. \& Richerson, P. J. 1985. Culture and the Evolutionary Process. Chicago: University of Chicago Press.

Cavalli-Sforza, L. \& Feldman, M. W. 1981. Cultural Transmission and Evolution: A Quantitative Approach. Princeton, New Jersey: Princeton University Press.

Clutton-Brock, T. H. 1991. The Evolution of Parental Care. Princeton, New Jersey: Princeton University Press.

Constanz, G. D. 1989. Reproductive biology of Poeciliid fishes. In: Ecology and Evolution of Livebearing Fishes (Ed. by G. K. Meffe \& F. F. Snelson), pp. 33-50. Princeton, New Jersey: Prentice Hall.

Coussi-Korbel, S. \& Fragaszy, D. M. 1995. On the relation between social dynamics and social learning. Animal Behaviour, 50, 14411453.

Davies, N. B. 1991. Mating systems. In: Behavioural Ecology: An Evolutionary Approach. 3rd edn (Ed. by J. R. Krebs \& N. B. Davies), pp. 263-94. Oxford: Blackwell Scientific.

Dussault, G. V. \& Kramer, D. L. 1981. Food and feeding behavior of the guppy, Poecilia reticulata (Pisces: Poeciliidae). Canadian Journal of Zoology, 59, 684-701.

Endler, J. A. 1995. Multiple-trait coevolution and environmental gradients in guppies. Trends in Ecology and Evolution, 10, 22-29.

Ferguson, G. A. 1965. Nonparametric Trend Analysis. Montreal: McGill University Press.

Fisher, J. \& Hinde, R. A. 1949. The opening of milk bottles by birds. British Birds, 42, 347-357.

Fragaszy, D. \& Visalberghi, E. 1989. Social influences on the acquisition of tool-using behaviors in tufted capuchin monkeys (Cebus apella). Journal of Comparative Psychology, 103, 159-170.

Fragaszy, D. M. \& Visalberghi, E. 1990. Social processes affecting the appearance of innovative behaviors in capuchin monkeys. Folia Primatologica, 54, 155-165.

Galef, B. G., Jr. 1992. The question of animal culture. Human Nature, 3, 157-178.

Griffiths, S. W. \& Magurran, A. E. 1997. Schooling preferences for familiar fish vary with group size in a wild guppy population. Proceedings of the Royal Society of London, Series B, 264, 547-551.

Griffiths, S. W. \& Magurran, A. E. 1998. Sex and schooling behaviour in the Trinidadian guppy. Animal Behaviour, 56, 689693.

Heyes, C. M. 1994. Social learning in animals: categories and mechanisms. Biological Reviews, 69, 207-231.
Itani, J. 1965. Japanese Monkeys: A Collection of Translations (Ed. by K. Imanishi \& S. A. Altmann), pp. 52-65. Edmonton: University of Alberta Press.

Katzir, G. 1982. Relationships between social structure and response to novelty in captive jackdaws, Corvus monedula L., I. Response to novel space. Behaviour, 81, 231-264.

Kawai, M. 1965. Newly-acquired pre-cultural behavior of the natural troop of Japanese monkeys on Koshima islet. Primates, 6, 1-30.

Krause, J. 1994. The influence of food competition and predation risk on size-assortative shoaling in juvenile chub (Leuciscus cephalus). Ethology, 96, 105-116.

Lachlan, R. F., Crooks, L. \& Laland, K. N. 1998. Who follows whom? Shoaling preferences and social learning of foraging information in guppies. Animal Behaviour, 56, 181-190.

Laland, K. N. \& Reader, S. M. 1999a. Foraging innovation in the guppy. Animal Behaviour, 57, 331-340.

Laland, K. N. \& Reader, S. M. 1999b. Foraging innovation is inversely related to competitive ability in male but not in female guppies. Behavioral Ecology, 10, 270-274.

Laland, K. N. \& Williams, K. 1997. Shoaling generates social learning of foraging information in guppies. Animal Behaviour, 53, $1161-1169$

Laland, K. \& Williams, K. 1998. Social transmission of maladaptive information in the guppy. Behavioral Ecology, 9, 493-499.

Lee, P. 1991. Adaptations to environmental change: an evolutionary perspective. In: Primate Responses to Environmental Change (Ed. by H. O. Box), pp. 39-56. London: Chapman \& Hall.

Lefebvre, L. 1995a. Culturally-transmitted feeding behaviour in primates: evidence for accelerating learning rates. Primates, 36, 227-239

Lefebvre, L. 1995b. The opening of milk bottles by birds: evidence for accelerating learning rates but against the wave-of-advance model of cultural transmission. Behavioural Processes, 34, 43-53.

Lefebvre, L. \& Palameta, B. 1988. Mechanisms, ecology, and population diffusion of socially learned, food-finding behavior in feral pigeons. In: Social Learning: Psychological and Biological Perspectives (Ed. by T. Zentall \& B. G. Galef), pp. 141-163. Hillsdale, New Jersey: L. Erlbaum.

Magurran, A. E., Seghers, B. H., Shaw, P. W. \& Carvalho, G. R. 1995. The behavioral diversity and evolution of guppy, Poecilia reticulata, populations in Trinidad. Advances in the Study of Behavior, 24, 155-202.

Milinski, M. 1993. Predation risk and feeding behaviour. In: Behaviour of Teleost Fishes. 2nd edn (Ed. by T. J. Pitcher), pp. 285-306. London: Chapman \& Hall.

Reznick, D. \& Yang, A. P. 1993. The influence of fluctuating resources on life-history patterns of allocation and plasticity in female guppies. Ecology, 74, 2011-2019.

Rogers, E. M. 1995. Diffusion of Innovations. 4th edn. New York: Free Press.

Sargent, R. C. \& Gross, M. R. 1993. Williams' principle: an explanation of parental care in teleost fishes. In: Behaviour of Teleost Fishes. 2nd edn (Ed. by T. J. Pitcher), pp. 333-361. London: Chapman \& Hall.

Seghers, B. 1974. Schooling behavior in the guppy (Poecilia reticulata): an evolutionary response to predation. Evolution, 28, 486489.

Sugita, Y. 1980. Imitative choice behavior in guppies. Japanese Psychological Research, 22, 7-12.

Trivers, R. L. 1972. Parent investment and sexual selection. In: Sexual Selection and the Descent of Man (Ed. by B. Campbell), pp. 136-179. Chicago: Aldine. 